\title{
ANALISIS EFISIENSI DAN EFEKTIVITAS PERFORMANSI LINE MACHINING PROPELLER SHAFT UNTUK PRODUK FLANGE MENGGUNAKAN METODE OVERALL EQUIPMENT EFFECTIVENESS (OEE) (STUDI KASUS DI PT HINO MOTORS MANUFACTURING INDONESIA)
}

\author{
Novia Setya Ningrum, Ahmad Muhsin \\ Program Studi Teknik Industri Fakultas Teknik Industri \\ Universitas Pembangunan Nasional "Veteran" Yogyakarta \\ Jl. Babarsari 2 Tambakbayan, Yogyakarta, 55281 \\ Telp. (0274) 485363 Fak : (0274) 486256 email : jur_tiupn@telkom.net
}

\begin{abstract}
ABSTRAK
PT Hino Motors Manufacturing Indonesia (HMMI) adalah sebuah perusahaan yang bergerak dalam bidang manufaktur perakitan truk dan bis, perakitan komponen dan ekspor suku cadang. Dalam proses produksi seringkali terjadi gangguan pada mesin atau peralatan yang digunakan, sehingga mengganggu jalannya proses produksi. Departemen machining propeller shaft PT HMMI yang memproduksi produk flange mengharapkan agar mesin yang beroperasi dapat menghasilkan produk sesuai dengan target produksi yang diinginkan.

Dalam penelitian ini, akan dilakukan identifikasi efektivitas mesin menggunakan metode Overall Equipment Effectiveness (OEE). OEE adalah metode pengukuran yang digunakan untuk menentukan performansi suatu mesin atau pelatan guna menjaga mesin atau peralatan tersebut pada kondisi yang baik. Dengan semakin tinggi nilai overall equipment effectiveness (OEE) maka biaya produksi akan lebih rendah namun kualitasnya tetap terjaga. Metode ini tidak memperhitungkan biaya pengoperasian peralatan melainkan menghitung availability, performance efficiency, dan quality rate sebagai indikatornya.

Berdasarkan analisis yang telah dilakukan pada line machining propeller shaft untuk produk flange di PT Hino Motors Manufacturing Indonesia dengan menggunakan metode Overall Equipment Effectiveness (OEE), nilai OEE sebesar 81,1\% belum memenuhi target standar JIPM sebesar $85 \%$. Rendahnya nilai OEE disebabkan karena downtime mesin sehingga mesin tidak bekerja produktif, waktu terbuang dan tidak menghasilkan produk stabil.
\end{abstract}

Keywords : Propeller, OEE, availability, performance efficiency, dan quality rate

\section{PENDAHULUAN}

PT Hino Motors Manufacturing Indonesia (HMMI) merupakan salah satu perusahaan yang bergerak di bidang manufaktur yang merakit truk, penyedia suku cadang dan machining komponen mesin. Departemen yang memproduksi komponen mesin adalah departemen Machining. Departemen machining memproduksi beberapa produk yaitu, Connecting rod Line, Camshaft Line, Crank Shaft, Cylinder Head, Cylinder Block, Propeller Shaft dan Axle. Pada propeller shaft, terdiri dari beberapa komponen yang diproduksi di line machining propeller shaft antara lain Axle 13', Sliding, Flange, Coupling, Center Bearing, Sliding, End Yoke, Nylon dan Main Assy.

Dalam proses produksi seringkali terjadi gangguan pada mesin atau peralatan yang digunakan, sehingga dapat mengganggu jalannya proses produksi. Gangguan ini dapat mengurangi keuntungan perusahaan serta mengurangi waktu aktif kerja yang dapat digunakan untuk proses produksi. Dengan adanya kerusakan pada mesin, maka akan 
membutuhkan waktu dan biaya yang cukup besar untuk melakukan perbaikan peralatan atau mesin.

Pada bulan Januari sampai Juli 2016, jumlah target produksi produk flange yang ditetapkan oleh perusahaan tidak stabil. Pada bulan Januari dan Juli target produksi terpenuhi, pada bulan Februari dan April hasil produksi melebihi target produksi, sedangkan pada bulan Maret, Mei dan Juni target produksi tidak terpenuhi. Ketidakstabilan tersebut dapat disebabkan oleh mesin atau operatornya. Maka, untuk mengetahui penyebab ketidakstabilan hasil produksi produk flange secara pasti perlu dilakukan pengamatan lebih lanjut.

Departemen machining propeller shaft PT HMMI yang memproduksi produk flange mengharapkan agar mesin yang beroperasi dapat menghasilkan produk sesuai dengan target produksi yang diinginkan. Dalam hal ini, akan dilakukan identifikasi efektivitas mesin menggunakan metode Overall Equipment Effectiveness (OEE).

Manfaat yang dapat diperoleh dari analisis tingkat efektivitas line machining propeller shaft untuk produk flange dengan metode OEE ini adalah perusahaan dapat mengetahui seberapa efektif line machining propeller shaft dapat beroperasi dalam memproduksi produk flange. Dengan mengetahui hal tersebut, perusahaan juga dapat melakukan perbaikan atau pencegahan kerusakan yang mungkin akan terjadi agar dapat meningkatkan produktivitas

\section{METODE PENELITIAN}

Di era globalisasi ini, perkembangan industri dalam bidang manufaktur di Indonesia mengalami kemajuan yang cukup pesat dari tahun ke tahun. Hal tersebut tentu saja membuat persaingan perusahaan menjadi kian ketat. Persaingan yang ketat ini mendorong setiap perusahaan agar selalu dapat menghasilkan produk yang berkualitas. Untuk dapat menghasilkan produk yang berkualitas maka kondisi peralatan atau mesin yang digunakan harus tetap terjaga. Agar kondisi mesin tetap terjaga maka dibutuhkan strategi perawatan yang tepat. Perawatan adalah kegiatan untuk memelihara atau menjaga fasilitas atau peralatan dan mengadakan perbaikan, penyesuaian dan penggantian yang diperlukan agar terdapat suatu kondisi sesuai dengan yang direncanakan (Assauri, 1980).

Flange adalah salah satu produk yang diproduksi pada line machining propeller shaft di PT HMMI. Nama asli flange sebenarnya adalah universal joint namun, di PT HMMI lebih dikenal dengan flange. Flange merupakan salah satu bagian yang terdapat pada propeller shaft. Flange ini berfungsi untuk memungkinkan poros berputar dengan lancer walaupun terjadi perubahan sudut.

Departemen machining di PT HMMI adalah departemen yang memproduksi komponen mesin yang akan digunakan pada truk dan bus. Departemen machining memproduksi beberapa produk yaitu, Connecting rod Line, Camshaft Line, Crank Shaft, Cylinder Head, Cylinder Block, Propeller Shaft dan Axle. Propeller shaft sendiri adalah salah satu bagian dari sistem pemindah tenaga yang berfungsi untuk meneruskan putaran dan daya mesin dari transmisi ke differensial dengan variasi perubahan sudut yang selalu terjadi pada poros tersebut saat memindahkan putaran dan daya.

Pada line machining propeller shaft terdiri dari beberapa komponen yang diproduksi, antara lain Axle 13', Sliding, Flange, Coupling, Center Bearing, Sliding, End Yoke, Nylon dan Main Assy. Berikut adalah gambar-gambar yang menunjukkan pemasangan propeller shaft pada badan truk/bus:

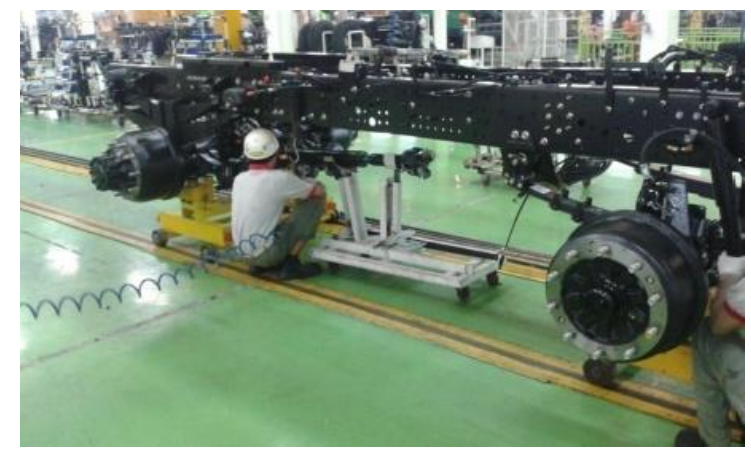

Gambar 1. Proses pemasangan propeller shaft 


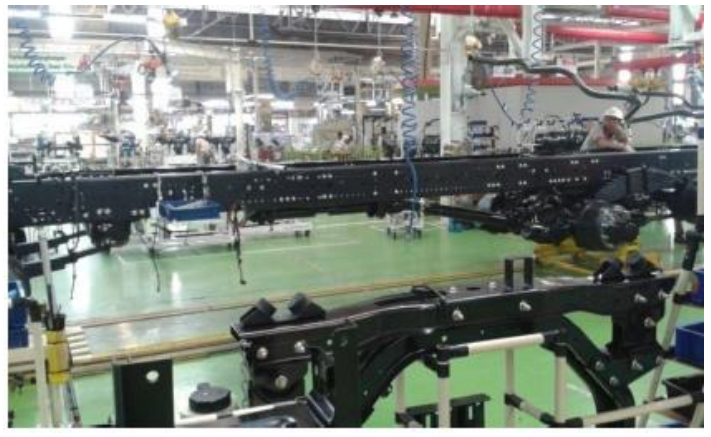

Gambar 2. Propeller shaft yang sudah terpasang

Overall Equipment Effectiveness (OEE) adalah besarnya efektivitas yang dimiliki oleh perusahaan atau mesin. OEE dihitung dengan memperoleh dari availabilitas dari alat-alat perlengkapan, efisiensi kerja dari proses, dan rasio dari mutu produk. OEE menunjukkan suatu indikator yang dapat memperlihatkan seberapa baik perusahaan menggunakan sumber daya yang dimilikinya (tingkat kehandalan, tingkat produktivitas, dan lain-lain) suatu peralatan atau mesin yang digunakan pada proses produksi (Nakajima dalam Prabowo, 2015).

OEE dapat digunakan dalam beberapa jenis tingkatan pada sebuah lingkaran perusahaan. Pertama OEE dapat digunakan sebagai "benchmark" untuk mengukur rencana perusahaan dalam performansi. Kedua, nilai OEE perkiraan dari satu aliran produksi, dapat digunakan untuk membandingkan garis performansi melintang dari perusahaan, maka akan terlihat aliran yang tidak penting. Ketiga, jika proses permesinan dilakukan secara individual, OEE dapat mengidentifikasi mesin mana yang mempunyai performansi buruk, bahkan mengidentifikasi fokus dari sumber daya Total Productive Maintenance (TPM).

Manfaat yang dapat diperoleh dari pengukuran OEE ini adalah perusahaan dapat mengetahui seberapa efektif kemampuan peralatan atau mesin yang dimilikinya, dan apakah masih layak atau tidak untuk digunakan dalam kegiatan produksi. Layak atau tidaknya peralatan atau mesin tersebut dapat dilihat dari target yang dibuat oleh perusahaan.

Hal-hal yang diperlukan dalam aplikasi Overall Equipment Effectiveness diperusahaan adalah dengan menghitung komponen OEE, yaitu:

\section{Availability Ratio}

Availability Ratio merupakan rasio yang menggambarkan pemanfaatan waktu yang tersedia untuk kegiatan operasi mesin atau peralatan.

Faktor penting Availability adalah loading time dan operating time. Loading time adalah total waktu produksi dalam sehari. Dengan demikian formula yang digunakan untuk menghitung availability ratio adalah:

$$
\text { Availability Rate }=\frac{\text { waktu operasi }}{\text { loading time }} \times 100 \%
$$

Waktu operasi $=$ loading time - down time

\section{Performance Efficiency}

Performance Efficiency merupakan suatu ratio yang menggambarkan kemampuan dari peralatan dalam menghasilkan barang atau produk yang dinyatakan dengan persentase. Adapun data-data yang digunakan dalam pengukuran Performance Efficiency adalah data jumlah produksi, ideal cycle time dan waktu operasi. Dengan demikian formula yang digunakan untuk menghitung Performance Efficiency adalah:

Performance Ratio $=\frac{\text { Jumlah produksi }}{\text { Ideal cycle time } \mathrm{x} \text { waktu operasi }} \times 100 \%$

\section{Rate of Quality Product}

Quality ratio merupakan suatu rasio yang menggambarkan kemampuan peralatan dalam menghasilkan produk yang sesuai dengan standar. Data yang digunakan dalam pengukuran quality ratio adalah jumlah produk yang diproduksi dan jumlah produk cacat dari produk yang berhasil diproduksi. Dengan demikian formula yang digunakan untuk menghitung quality ratio adalah:

Quality Rate $=\frac{\text { Jumlah produksi-Jumlah produk cacat }}{\text { Jumlah produksi }} \times 100 \%$ 
Dari ketiga faktor diatas maka dapat dilakukan pengukuran untuk Overall Equipment Effectiveness (OEE). Formula yang digunakan untuk menghitung OEE adalah :

$\mathrm{OEE}=$ Availability $\mathrm{x}$ Performance efficiency x Rate of Quality Product

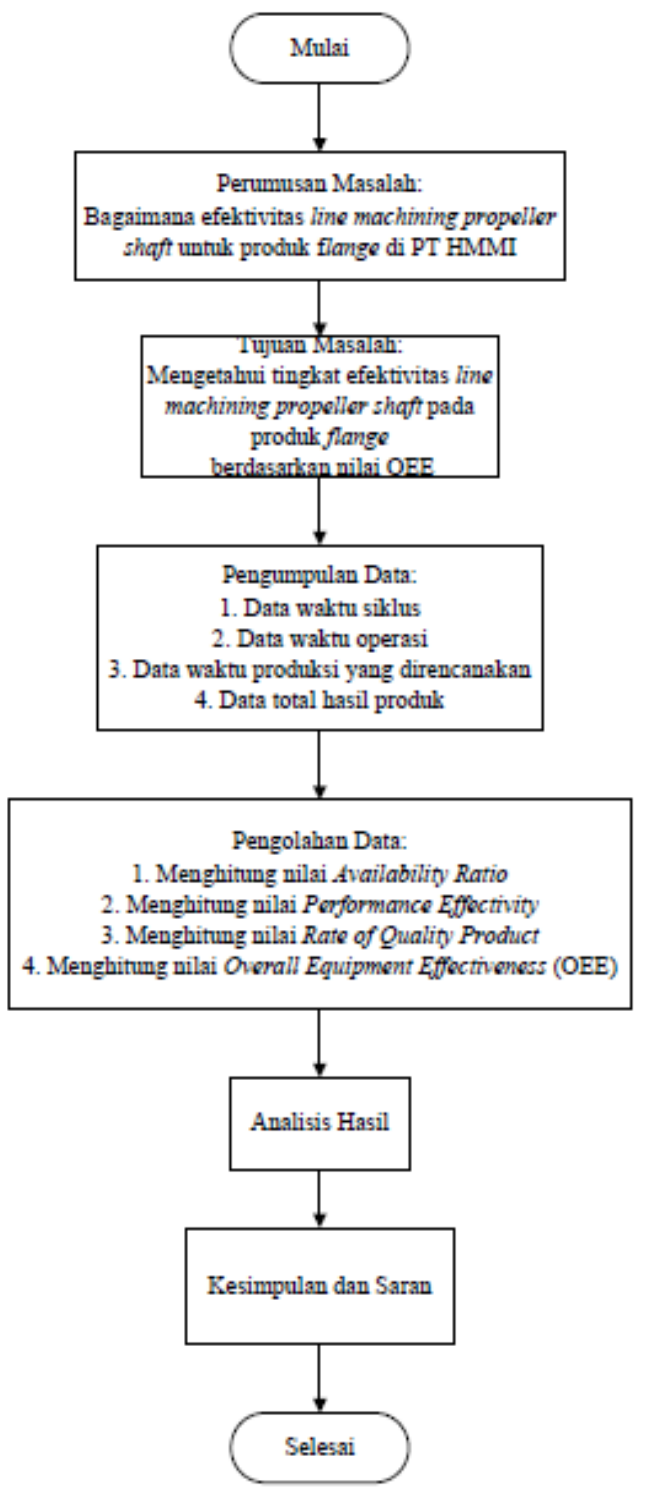

Gambar 1 Diagram alur penelitian

Untuk mendapatkan data yang diperlukan dalam melakukan penelitian, maka digunakan data yang terdiri dari dua jenis, yaitu:

\section{Data Primer}

Data diperoleh langsung dari sumbernya. Data ini didapat dengan cara wawancara dengan pihak-pihak yang berkaitan dengan penelitian ini dan melakukan observasi terhadap objek yang diteliti.

2. Data Sekunder

Data sekunder meliputi semua data yang didapat dari luar tempat Data yang digunakan dalam penyelesaian laporan ini adalah data downtime produk flange pada line machining propeller shaft periode Januari-Juli 2016.

\section{HASIL DAN PEMBAHASAN}

Dalam penelitian yang dilakukan di PT Hino Motors Manufacturing Indonesia didapatkan data-data yang mendukung untuk melakukan perhitungan efektivitas pada line machining propeller shaft untuk produk flange dengan metode Overall Equipment Effectiveness (OEE). Data-data yang dibutuhkan untuk melakukan perhitungan OEE ini meliputi :

Tabel 1. Data kebutuhan OEE

\begin{tabular}{|c|c|c|c|c|c|c|}
\hline Periode & $\begin{array}{c}\text { Waltu Operasi } \\
\text { (menit) }\end{array}$ & $\begin{array}{c}\text { Loading Time } \\
\text { (menit) }\end{array}$ & $\begin{array}{c}\text { Dointizite } \\
\text { (menit) }\end{array}$ & $\begin{array}{c}\text { Idenl Cycle } \\
\text { Time } \\
\text { (menit/pcs) }\end{array}$ & $\begin{array}{c}\text { Jumlah } \\
\text { Produksi (pcs) }\end{array}$ & $\begin{array}{c}\text { Jumlah Cacat } \\
\text { (pcs) }\end{array}$ \\
\hline Jamuari & 9626 & 9990 & 364 & 1.88 & 4272 & 48 \\
\hline Februari & 8006 & 8115 & 109 & 1.88 & 3610 & 47 \\
\hline Maret & 9159 & 9370 & 211 & 1.88 & 3945 & 40 \\
\hline April & 11502 & 12033 & 531 & 1.88 & 5340 & 70 \\
\hline Mei & 11095 & 11590 & 495 & 1.88 & 5220 & 98 \\
\hline Juni & 10900 & 11505 & 605 & 1.88 & 4763 & 48 \\
\hline Juli & 7954 & 8342 & 388 & 1.88 & 3792 & 41 \\
\hline
\end{tabular}

(Sumber. Dept. Machining Propeller Shaft PT HMM, 2016)

Hal-hal yang perlu dihitung dalam perhitungan Overall Equipment Effectiveness (OEE) sebagai berikut :

1. Pengukuran Availability Ratio Pengukuran availability ratio untuk bulan Januari 2016 adalah sebagai berikut:

Availability ratio $=\frac{\text { Waktu operasi }}{\text { Loading time }} \times 100 \%$

$=\frac{9626}{9990} \times 100 \%$

$=96,3 \%$ 
Dengan cara yang sama, hasil perhitungan availability ratio pada bulan Januari-Juli 2016 seperti pada Tabel

Tabel 2. Hasil perhitungan availability ratio

\begin{tabular}{|c|c|c|c|c|}
\hline Periode & $\begin{array}{c}\text { Waktu Operasi } \\
\text { (menit) }\end{array}$ & $\begin{array}{c}\text { Loading Time } \\
\text { (menit) }\end{array}$ & $\begin{array}{c}\text { Downtime } \\
\text { (menit) }\end{array}$ & $\begin{array}{c}\text { Availability } \\
\text { Ratio(\%) }\end{array}$ \\
\hline Januari & 9626 & 9990 & 364 & 96.3 \\
\hline Februari & 8006 & 8115 & 109 & 98.6 \\
\hline Maret & 9159 & 9370 & 211 & 97.7 \\
\hline April & 11502 & 12033 & 531 & 95.6 \\
\hline Mei & 11095 & 11590 & 495 & 95.7 \\
\hline Juni & 10900 & 11505 & 605 & 94.7 \\
\hline Juli & 7954 & 8342 & 388 & 95.3 \\
\hline
\end{tabular}

2. Pengukuran Performance Efficiency.

Pengukuran performance efficiency untuk bulan Januari 2016 adalah sebagai berikut:

$$
\begin{aligned}
\text { Performance efficiency } & =\frac{\text { Jumlah produksi }}{\text { ldeal cycle time } \mathrm{x} \text { Waktu operasi }} \times 100 \% \\
& =\frac{4272}{1,88 \times 9626} \times 100 \% \\
& =83,6 \%
\end{aligned}
$$

Dengan cara yang sama, hasil perhitungan performance efficiency pada bulan JanuariJuli 2016 seperti pada Tabel

Tabel 3 Hasil perhitungan performance efficiency

\begin{tabular}{|c|c|c|c|c|}
\hline Periode & $\begin{array}{c}\text { Jumlah } \\
\text { Produksi } \\
\text { (pcs) }\end{array}$ & $\begin{array}{c}\text { Ideal Cycle } \\
\text { Time } \\
\text { (detik/pcs) }\end{array}$ & $\begin{array}{c}\text { Waktu Operasi } \\
\text { (menit) }\end{array}$ & $\begin{array}{c}\text { Performance } \\
\text { Efficiency Rate } \\
\text { (\%) }\end{array}$ \\
\hline Januari & 4272 & 1.88 & 9626 & 83.6 \\
\hline Februari & 3610 & 1.88 & 8006 & 85 \\
\hline Maret & 3945 & 1.88 & 9159 & 81.1 \\
\hline April & 5340 & 1.88 & 11502 & 87.4 \\
\hline Mei & 5220 & 1.88 & 11095 & 88.6 \\
\hline Juni & 4763 & 1.88 & 10900 & 82.3 \\
\hline Juli & 3792 & 1.88 & 7954 & 89.8 \\
\hline
\end{tabular}

3. Pengukuran Rate of Quality Product Pengukuran rate of quality product untuk bulan Januari 2016 adalah sebagai berikut:

$$
\begin{aligned}
\text { Quality ratio } & =\frac{\text { Jumlah produksi- Jumlah produk cacat }}{\text { Jumlah produk }} \times 100 \% \\
& =\frac{4272-48}{4272} \times 100 \% \\
& =98,8 \%
\end{aligned}
$$

Dengan cara yang sama, hasil perhitungan rate of quality product pada bulan JanuariJuli 2016 seperti pada Tabel

Tabel 4. Hasil perhitungan rate of quality

\begin{tabular}{|c|c|c|c|}
\hline Periode & $\begin{array}{c}\text { Jumlah } \\
\text { Produksi (pcs) }\end{array}$ & $\begin{array}{c}\text { Jumlah } \\
\text { Cacat (pcs) }\end{array}$ & $\begin{array}{c}\text { Quality Rate } \\
(\%)\end{array}$ \\
\hline Januari & 4272 & 48 & 98.8 \\
\hline Februari & 3610 & 47 & 98.7 \\
\hline Maret & 3945 & 40 & 99 \\
\hline April & 5340 & 70 & 98.7 \\
\hline Mei & 5220 & 98 & 98.1 \\
\hline Juni & 4763 & 48 & 99 \\
\hline Juli & 3792 & 41 & 99 \\
\hline
\end{tabular}

\section{Perhitungan Overall Equipment Effectiveness (OEE)}

Pengukuran overall equipment effectiveness (OEE) untuk bulan Januari 2016 adalah sebagai berikut:

$$
\begin{aligned}
\text { OEE } & =\text { Availability } \times \text { Performance efficiency } \times \text { Rate of Quality Product } \\
& =96,3 \% \times 83,6 \% \times 98,8 \% \\
& =79,5 \%
\end{aligned}
$$

Dengan cara yang sama, hasil perhitungan OEE pada bulan Januari-Juli 2016 seperti pada Tabel

Tabel 5 Hasil perhitungan OEE

\begin{tabular}{|c|c|c|c|c|}
\hline Periode & $\begin{array}{c}\text { Availability } \\
\text { Ratio (\%) }\end{array}$ & $\begin{array}{c}\text { Performance } \\
\text { Efficiency (\%) }\end{array}$ & $\begin{array}{c}\text { Quality } \\
\text { Ratio (\%) }\end{array}$ & $\begin{array}{c}\text { Overall Equipment } \\
\text { Effectiveness (\%) }\end{array}$ \\
\hline Januari & 96.3 & 83.6 & 98.8 & 79.5 \\
\hline Februari & 98.6 & 85 & 98.7 & 82.7 \\
\hline Maret & 97.7 & 81.1 & 99 & 78.4 \\
\hline April & 95.6 & 87.4 & 98.7 & 82.4 \\
\hline Mei & 95.7 & 88.6 & 98.1 & 83.2 \\
\hline Juni & 94.7 & 82.3 & 99 & 77.1 \\
\hline Juli & 95.3 & 89.8 & 99 & 84.7 \\
\hline \multicolumn{5}{|c|}{ Rata-rata } \\
\hline
\end{tabular}


Dalam bentuk grafik, pencapaian nilai OEE yang telah dihitung dapat dilihat pada Gambar

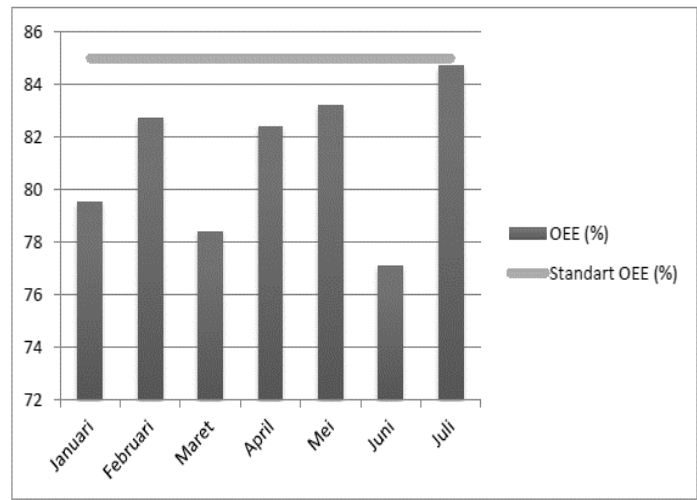

Gambar 3. Grafik OEE line machining propeller shaft

Dari Gambar 3 dapat diketahui bahwa OEE pada line machining propeller shaft untuk produk flange periode JanuariJuli 2016 belum memenuhi standar. Diperlukan tindakan perbaikan agar mesin dapat mencapai nilai standar OEE dan dapat beroperasi dengan baik sehingga menghasilkan produk secara stabil sesuai dengan target produksi yang telah ditetapkan.

Berdasarkan hasil perhitungan nilai availability yang dapat dilihat pada tabel 2 , diketahui bahwa nilai yang diperoleh pada setiap periode sudah memenuhi standar yang dikeluarkan oleh JIPM dan perusahaan yaitu $90 \%$. Hasil tersebut adalah hasil yang sudah cukup memuaskan, karena akan sangat sedikit kemungkinan perusahaan mengalami kerugian karena tingkat availability yang rendah.

Perhitungan nilai performance efficiency yang diperoleh, dapat diketahui bahwa hasil tersebut belum memenuhi standar yang dikeluarkan oleh JIPM dan perusahaan yaitu sebesar 95\%. Hal ini terbukti dari nilai performansi yang ditunjukkan pada tabel 3 Dari tabel tersebut terlihat bahwa nilai performansi pada line machining propeller shaft untuk produk flange yang paling tinggi ada pada periode bulan Juli yaitu sebesar $89,8 \%$. Sedangkan untuk performansi paling rendah ada pada periode bulan Maret yaitu sebesar $81,1 \%$.
Rendahnya tingkat performansi ini dapat disebabkan karena tingginya permintaan konsumen dan tingginya waktu yang tidak menghasilkan produk. Oleh karena itu, perlu dilakukannya peningkatan kapasitas dan melakukan pengecekkan pada line machining propeller shaft agar dapat memenuhi permintaan konsumen dan mengetahui apa yang menyebabkan tingginya waktu yang tidak menghasilkan produk.

Pada hasil perhitungan rate of quality product yang dapat dilihat pada tabel 4, diketahui bahwa nilai quality ratio tersebut sudah memenuhi standar JIPM dan perusahaan yaitu 99\%. Walaupun pada periode bulan Januari menghasilkan quality ratio $98,8 \%$, Februari dan April 98,7\%, dan Mei sebesar 98,1\%, namun hasil tersebut sudah mendekati standar yang ditetapkan dan dianggap tidak bermasalah oleh perusahaan. Kemudian untuk hasil perhitungan Overall Equipment Effectiveness (OEE) pada tabel 5 dapat dilihat bahwa nilai OEE pada line machining propeller shaft untuk produk flange belum memenuhi standar JIPM dan juga standar yang telah ditetapkan oleh perusahaan yaitu sebesar $85 \%$. Dari tabel tersebut, diketahui bahwa periode bulan Juli adalah periode yang menghasilkan nilai OEE tertinggi yaitu $84,7 \%$ dan periode bulan Juni adalah periode yang menghasilkan nilai OEE terendah yaitu $77,1 \%$.

Rata-rata yang didapat dari perhitungan ini adalah sebesar $81,1 \%$. Hal ini membuktikan bahwa nilai OEE pada periode Januari-Juli 2016 belum memenuhi standar. Penyebab rendahnya nilai OEE disebabkan karena tingginya downtime pada mesin yang terjadi setiap bulannya, sehingga menyebabkan waktu terbuang dan line machining propeller shaft yang menghasilkan produk flange tidak dapat bekerja secara produktif. 


\section{KESIMPULAN}

Berdasarkan analisis yang telah dilakukan pada line machining propeller shaft untku produk flange di PT Hino Motors Manufacturing Indonesia dengan menggunakan metode Overall Equipment Effectiveness (OEE), dapat disimpulkan sebagai berikut :

1. Nilai OEE yang didapat dari hasil perhitungan belum memenuhi target atau standar JIPM dan standar yang telah ditetapkan oleh perusahaan yaitu sebesar $85 \%$. Rata-rata yang didapat dari perhitungan OEE hanya sebesar $81,1 \%$.

2. Rendahnya nilai rata-rata OEE yang diperoleh disebabkan karena terjadinya downtime pada mesin yang cukup tinggi setiap bulannya. Tingginya downtime yang terjadi menimbulkan mesin tidak dapat bekerja secara produktif, menyebabkan waktu terbuang dan tidak menghasilkan produk atau hasil produksi tidak stabil.

Berdasarkan hasil penelitian yang telah dilakukan, perusahaan disarankan untuk:

1. Memperbaiki sistem pemeliharaan line machining propeller shaft untuk produk flange guna mencegah terjadinya downtime yang lama dan agar dapat mengurangi penyebab kerugiankerugian besar yang akan terjadi pada perusahaan.

2. Mengevaluasi intensitas perawatan yang dilakukan saat ini berdasarkan nilai OEE.

3. Mempertimbangkan metode OEE sebagai metode pengukuran performansi pada peralatan-peralatan produksi lainnya yang dimiliki oleh PT HMMI.

\section{DAFTAR PUSTAKA}

Assauri, Sofjan., 1980, Manajemen Produksi, Fakultas Ekonomi Universitas Indonesia, Jakarta.

Betrianis dan Suhendra, R, Pengukuran Nilai Overall Equipment Effectivenees Sebagai Dasar Usaha Perbaikan Proses Manufaktur Pada Lini Produksi (Studi Kasus pada Stamping Production Division Sebuah Industri Otomotif), Departemen Teknik Industri Fakultas Teknik, Universitas Indonesia.

Anonim, 2015, Bab II Deskripsi Perusahaan, http://digilib.mercubuana.ac.id/man ager/n!@file_skripsi/Isi275944949 7760.pdf, diakses pada bulan Juli 2016.

Nakajima, S., 1988. Introduction to Total Productive Maintenance, Productivity Press Inc, Portland, p. 21.

Otomobil, B., 2013, Ini Dia Proses Pembuatan Truk Hino, http://otomotifnet.com/Mobil/News -Apm/Ini-Dia-Proses-PembuatanTruk-Hino, diakses tanggal 3 November 2016.

Pambudi, A, W, S., 2015, Laporan Kerja Praktek di PT Hino Motors Manufacturing Indonesia, Departemen Teknik Mesin Sekolah Mesin, Universitas Gajah Mada, Yogyakarta.

Sitinjak, Y. R. E., Rahman, A., dan Efranto, R, Y., Analisis Total Productive Maintenance Pada Mesin Carding Cotton Dengan Metode Overall Equipment Effectiveness (Studi Kasus: PT. Easterntex - Pandaan), Jurusan Teknik Industri, Universitas Brawijaya.

Wentz, Charles, A., 1995, "Hazardous Waste Management", Second edition. Mc Graw Hill International Editions, United States.

Ratman, C. R., dan Syafrudin., 2010, Penerapan Pengelolaan Limbah B3 Di PT Toyota Motor Manufacturing 
Indonesia, Jurnal Presipitasi, Vol. 7

No. 2, Hal. 64 ISSN 1907-187X. 